\title{
PRINCÍPIOS FILOSÓFICOS E PEDAGÓGICOS DA EDUCAÇÃO NATURAL EM ROUSSEAU: UMA INVESTIGAÇÃO SOBRE O SEGUNDO LIVRO DO ÉMILE*
}

\author{
Claudio A. Dalbosco**
}

\begin{abstract}
RESUMO: O presente trabalho reconstrói o conteúdo de dois princípios que caracterizam o projeto de educação natural exposto por Rousseau no segundo livro do Émile. Investiga basicamente duas questões: Qual é o conteúdo de tais princípios? Em que base filosófica e pedagógica Rousseau os ampara? O primeiro princípio refere-se à dinâmica tensional do ser humano como constitutiva da ideia de infância; o segundo compreende o caráter negativo da educação natural. A exposição destes dois princípios pretende indicar o quanto é importante que o adulto proteja a criança, em seu desenvolvimento inicial, da invasão destruidora dos vícios e da artificialidade da sociedade. Desse modo, a difícil e complexa tarefa do educador pode ser atenuada na medida em que este tiver clareza dos princípios sob os quais repousa a ideia de educação natural.
\end{abstract}

Palavras-chave: Criança. Educação negativa. Ser humano. Desejo. Necessidade natural.

NATURAL EDUCATION'S PHILOSOPHICAL AND PEDAGOGICAL PRINCIPLES IN ROUSSEAU: AN INVESTIGATION ON THE SECOND BOOK OF ÉMILE

ABSTRACT: This paper rebuilds the content of two principles that characterize the project of natural education which is exposed by Rousseau in Émile's second book. It investigates basically two questions: what is the content of such principles? On what philosophical and pedagogical groundwork does Rousseau support them? The first principle refers to the tensional distance of the human being as constructive of the infancy idea, and the second one embraces the negative character of natural education. The exposition of those principles intends to show how important it is that the adult protect the child in its initial development from the destructive invasion of vices and of the artificiality of society. Thus, the hard and complex task of the

\footnotetext{
* $\quad$ Agradeço ao CNPq pela Bolsa Produtividade em Pesquisa, a qual me permitiu a realização desta pesquisa.

* Doutor em Filosofia e professor do Programa de Pós-Graduação em Educação e do Curso de Filosofia da Universidade de Passo Fundo (UPF). E-mail: vcdalbosco@hotmail.com
} 
educator may be attenuated as the principles on which the idea of natural education rests is clear for them.

Key words: Child. Negative education. Human being. Wish. Natural need.

\title{
PRINCIPES PHILOSOPHIQUES ET PEDAGOGIQUES DE L'EDUCATION NATURELLE CHEZ ROUSSEAU: UNE INVESTIGATION SUR LE SECOND LIVRE DU EMILE
}

\begin{abstract}
RÉSUMÉ: Le présent travail reconstruit le contenu des deux principes qui caractérisent le projet d'éducation naturelle exposé par Rousseau dans le second livre du Émile. Il investigue essentiellement deux questions: Quel est le contenu de tels principes? Sur quelle base philosophique et pédagogique Rousseau les soutenait-il? Le premier principe se réfère à la dynamique tensionnelle de l'être humain comme constitutive de l'idée d'enfance; le second contient le caractère négatif de l'éducation naturelle. L'exposition de ces deux principes vise à indiquer combien il est important que l'adulte protège l'enfant, dans son développement initial, contre l'invasion destructrice des vices et de l'artificialité de la société. De cette manière, la difficile et complexe tâche de l'éducateur peut être atténuée dans la mesure où celui-ci aura la clarté des principes sur lesquels repose l'idée de l'éducation naturelle.
\end{abstract}

Mots-clés: Enfant. Education négative. Etre humain. Désir. Nécessité naturelle.

\section{Introdução}

$\mathrm{N}$

o presente trabalho pretendemos reconstruir o conteúdo de dois dos mais importantes princípios que caracterizam o projeto de educação natural exposto por Rousseau no segundo livro do Émile. Nossa exposição investiga basicamente duas questões: Qual é o conteúdo de tais princípios? Em que base filosófica e pedagógica Rousseau os ampara?

Para efeito didático, faz-se necessário, primeiro, inserir a ideia de educação natural na estrutura geral do Émile, visualizando, brevemente, o lugar que ocupa nesta obra, uma vez que não é o único projeto nela desenvolvido e, por isso, não poderia dar conta, obviamente, do processo de formação humana como um todo. Pelo contrário, a educação natural ${ }^{1}$ (éducation particulière) compreende o desenvolvimento inicial do ser humano, tratando da criança em sua infância tripartite: primeira, segunda e terceira infâncias. No que diz respeito à estrutura geral da obra, o esboço de tal projeto é exposto, sobretudo, nos três primeiros livros. Ele é sucedido pelo projeto de educação social (éducation du monde), no qual Rousseau alinhava, no quarto e quinto livros, os princípios orientadores da inserção definitiva de seu aluno fictício na sociedade, quando este se encontra já em plena juventude.

A globalidade do seu projeto educacional, desenvolvida nos cinco livros do Émile, contém, portanto, duas dimensões ou etapas bem distintas: a educação natural 
(éducation domestique) e a educação social (éducation publique). Enquanto a primeira visa à formação do "homem físico", abarcando a idade da necessidade, da natureza e da força, a educação social destina-se à formação do "homem civil", em seus aspectos moral, jurídico e político, correspondendo à idade da razão e da sabedoria. Embora distintas entre si, tais etapas encontram-se profundamente entrelaçadas, pois seria inimaginável, segundo Rousseau, pensar o homem físico desconectado do homem civil e este, por sua vez, sem a noção de pertença a ordem das coisas. De qualquer modo, o projeto possui, na sua integra, a meta de formar um homem ideal, com "a razão de um sábio e o vigor de um atleta - la raison d'un sage et la vigueur d'un athléte" (OC IV, 362; 1992, p. 113). ${ }^{2}$

Como a formação do homem sábio e vigoroso é resultado de um longo processo educativo, que deve iniciar já com o nascimento do ser humano, compete à educação natural, concentrando-se especificamente na infância, organizar o processo pedagógico de tal forma que possa contribuir para o fortalecimento do corpo e o refinamento dos sentidos da criança. Tal organização está sustentada por uma base normativa clara, contendo princípios, conteúdo e aspectos metodológicos da educação natural. Mesmo que nossa exposição se concentre somente na abordagem dos princípios (em apenas dois deles), seremos levados a considerar alguns conceitos que constituem a educação natural, como a noção de ser humano e de infância, as necessidades da criança, os cuidados do adulto e, sobretudo, a relação entre educador e educando no contexto da educação pelas coisas.

Embora Rousseau não ofereça uma exposição sistemática dos princípios que constituem seu projeto de educação natural, considerando o núcleo da argumentação desenvolvida no segundo livro do Émile, podemos resumi-los nos dois seguintes: 1) na dinâmica tensional do ser humano como constitutiva da ideia de infância; 2) no caráter negativo da educação natural. Na sequência, vamos tratar de cada um destes princípios, buscando investigar o conteúdo que os definem.

\section{O homem em sua dinâmica tensional: desejar e poder; amor de si e amor próprio}

Um das principais objeções que Rousseau dirige à educação de sua época consiste em acusá-la de não possuir um conhecimento adequado da criança e, por isso, ao igualar a inteligência da criança à inteligência do adulto, adota a razão como critério exclusivo do processo formativo da criança. Até um autor do porte de Locke, ${ }^{3}$ cuja contribuição para a inovação das ideias pedagógica do século XVIII é inegável, foi acusado por Rousseau de só querer raciocinar com as crianças. ${ }^{4}$ Neste contexto, o âmbito da crítica do genebrino pressupõe, primeiramente, a ideia de que não é possível pensar a educação sem uma noção de homem e, em segundo lugar, evitar 
basear tal noção em pressupostos que impeçam a compreensão adequada do processo pedagógico. Ou seja, para Rousseau, as questões filosófico-pedagógicas centrais - por exemplo, como o ser humano conhece e aprende - dependem, em última instância, da questão acerca de quem é o próprio homem. É este questionamento que o conduz à crítica da antropologia filosófica clássica. Sob este aspecto, o próprio Émile pode ser lido como um esforço de distanciamento teórico da noção de homem como um animal racional constituído por uma essência pronta, independente da sociabilidade e da historicidade.

Tributária da tradição intelectualista, a éducation barbare ${ }^{5}$ faz repousar seu ideal pedagógico unicamente na ideia de homem como um animal racional, cujo sentido da existência e da significação de mundo resultaria do emprego de sua razão. Está implícita aí a ideia de que é pelo uso adequado de seu intelecto que o homem pode reconquistar sua perfeição, a qual ele já possui em sua interioridade, de modo inato, mas a esqueceu devido aos atrapalhos e às distrações causados pelo mundo sensível. Conhecer significa, neste contexto, redescobrir progressivamente a estrutura constitutiva do intelecto puro, para poder ter acesso ao inteligível. O sentido metafísico de formação aí subjacente consiste na noção de alma (espírito) como essência pronta, cuja verdade reside na sua própria interioridade e cujo acesso a ela depende da recusa decidida dos sentidos ou, pelo menos, da independização do intelecto em relação a eles.

É no bojo da crítica à educação bárbara que se evidencia, portanto, a crítica ao conceito de homem como animal racional. A preocupação com o homem e sua natureza não é algo específico do Émile, pois remonta ainda aos anos de 1950 da produção rousseauniana, especialmente ao Segundo discurso. Nesta obra, tanto o diagnóstico da sociedade presente e seu estado de profunda corrupção e artificialidade, como a contraposição a ela de um modelo ideal de sociedade dependem, em última instância, da investigação da natureza humana. Rousseau pensa que a resposta satisfatória à pergunta pela origem da desigualdade entre os homens deve conduzir à investigação acerca dos fundamentos da sociabilidade humana, a qual, por sua vez, remete à pergunta mais fundamental sobre quem é o próprio homem. Ele se põe, retoricamente, no prefácio ao Segundo discurso, a seguinte pergunta:

Considero, ainda, o assunto deste discurso como uma das questões mais interessantes que a filosofia possa propor e, infelizmente, para nós, como uma das mais espinhosas a que possam responder os filósofos, pois, como conhecer a fonte da desigualdade entre os homens, se não se começar a conhecer a eles mesmos? (OC III, 122; 1978, p. 227)

O percurso do Segundo discurso é claro: o intuito de apreender o homem tal como ele "saiu das mãos da natureza", ou seja, em sua constituição original, conduz Rousseau a desenvolver o construto do homem natural, opondo-o ao homem civil. A 
convicção de fundo, contra os jusnaturalistas da época, também é clara: o "estudo do homem originário, de suas verdadeiras necessidades e dos princípios fundamentais de seus deveres" é considerado como "único meio" para enfrentar as dificuldades relacionadas à "origem da desigualdade moral [e aos] verdadeiros fundamentos do corpo político [...] (OC III, 126; 1978, p. 231). Não é, portanto, projetando a sociedade para dentro do estado de natureza, mas sim, ao contrário, buscando compreendê-la a partir da ideia normativa de homem natural que é possível se aproximar da questão sobre a origem da desigualdade entre os homens.

Não podemos seguir aqui, em detalhes, os passos do argumento desenvolvido no Segundo discurso. Para nossos propósitos, interessa tão somente reter, de seu

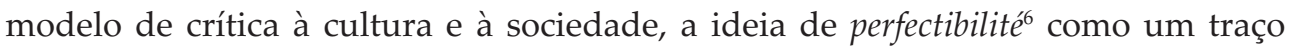
característico do homem que, ao mesmo tempo, distancia a posição rousseauniana da concepção intelectualista. A perfectibilité surge, ao lado da liberdade, como um fator decisivo na sociabilidade humana: é por meio desta permanente capacidade de se aperfeiçoar que o homem pode romper progressivamente com a fixidez de sua carga instintiva e, com isso, produzir cultura. Rousseau a define como "faculdade que, com o auxílio das circunstâncias, desenvolve sucessivamente todas as outras e se encontra, entre nós, tanto na espécie como no indivíduo [...]" (OC III, 142; 1978, p. 243). Como poder de desenvolver todas as outras faculdades, a perfectibilité pode ser compreendida como "faculdade das faculdades" e, como tal, permite ao homem a indeterminabilidade, ou seja, o caráter aberto e maleável de seu comportamento, capacitando-o a ir além de uma determinação prévia e absoluta.

Não é difícil perceber o quanto esta ideia torna-se produtiva para o âmbito da formação e educabilidade humana: ela caracteriza o facto antropológico-pedagógico de que a "natureza humana"7 é capaz tanto de se deixar moldar como de moldar-se a si mesma, caracterizando, portanto, em última instância, o próprio fato da educabilidade humana. Ora, esta dimensão antropológico-filosófica da ideia de perfectibilidade do Segundo discurso receberá, no Émile, uma direção pedagógica bem determinada, colocando-se na base da ideia de formação humana como um processo aberto e impossível de ser determinado pelo educador previamente, de modo absoluto e definitivo. No contexto da educação natural, como ainda veremos adiante, as referências maiores, no caso da educação da criança, devem ser dadas pela natureza e não pela sociedade.

Voltemo-nos agora, especificamente, para o Émile. Aí aparecem dois traços distintivos da natureza humana que terão importância pedagógica decisiva, servindo, ao mesmo tempo, para balizar a diferença de postura assumida por Rousseau em relação à antropologia metafísica. Refiro-me a dupla tensão: entre o querer (desejar) e o poder e entre o amor de si e o amor próprio. No que diz respeito, especificamente, à tensão entre desejar e poder, ela é crucial à educação natural, na medida em que 
seu tratamento adequado pode evitar que a criança queira impor suas necessidades de fantasia, escravizando o adulto ao seu bel prazer.

Esta tensão talvez seja uma das principais referências empregadas por Rousseau para compreender a criança como criança e para evitar, com isso, que ela seja corrompida pela ação viciada do adulto. De outra parte, do conhecimento desta dinâmica tensional depende também o esclarecimento do caráter negativo da educação natural e, com ela, de uma de suas principais diferenças em relação à educação bárbara.

Pode-se afirmar que o homem e, de modo especial, a criança são, para Rousseau, um ser desejante e isso no sentido de que são seus desejos (desirs) que o impulsionam a sair de si, a comparar-se com os demais e, neste ato de comparação, buscar ser mais do que os seus semelhantes. Da dinâmica do homem como um ser desejante, isto é, de um ser que quer (que possui uma volonté), brota não só seu impulso para a autoconservação como também sua aspiração por reconhecimento. Na ideia de desejo esconde-se, portanto, não só a satisfação das necessidades básicas, como também daquelas que impulsionam o homem à construção dos laços sociais e à significação simbólica de tais laços, isto é, que o impulsionam para sua sociabilidade e para a produção cultural. $\mathrm{O}$ fato de que o homem seja um ser desejante não é, em princípio, nenhum problema para Rousseau, mas torna-se um quando o próprio homem não consegue pôr adequadamente seus desejos e nem equilibrar a satisfação dos mesmos. Mais precisamente, o problema surge no descompasso entre os desejos e as faculdades: "Na desproporção entre nossos desejos (desirs) e faculdades (facultés) está aquilo em que consiste nossa miséria" (OC IV, 303-304; 1992, p. 62).

Podemos nos perguntar agora em que medida este problema afeta a vida da criança. Ou seja, em que medida ele se torna um problema relevante para a noção de infância e como a educação natural pode enfrentá-lo adequadamente? A posição do problema nesses termos auxilia-nos a ver a distância antropológico-pedagógica da educação natural em relação à educação bárbara. Pelo fato de considerar a criança mais um ser racional do que sensível, a educação bárbara possui a tendência de ignorar a dimensão desejante da criança ou, quando a toma em consideração, o faz com a intenção clara de reprimi-la. É justamente neste sentido que se deixa esclarecer a objeção de Rousseau de que ela não conhece adequadamente a criança, desrespeitando-a como criança: a educação bárbara procede assim justamente por desconhecer ou por não levar devidamente a sério o fato de que a criança é, antes de tudo, um ser desejante.

Ao fazer isso, ela se ocupa somente com a formação das "faculdades racionais" da criança, deixando de considerar devidamente suas necessidades reais, as quais poderiam inclusive ser utilizadas como critério limitante da própria ampliação abusiva 
dos desejos. Por isso, ao querer somente "raciocinar com as crianças", a pedagogia intelectualista, além de não conhecer adequadamente as suas necessidades reais da criança, torna-se impotente para tratar pedagogicamente de suas necessidades artificiais. Em síntese, por desconhecer ou ignorar a tensão entre necessidades reais e de fantasia que constitui o mundo infantil, tal pedagogia torna seus métodos infrutíferos para tratar da criança.

Isso é suficiente para deixar claro, de outra parte, que a tarefa da educação natural consiste na busca do equilíbrio entre os desejos e as faculdades, pois querer formar em excesso as faculdades da criança, reprimindo seus desejos, significa não compreendê-la adequadamente. Significaria, bem ao contrário, como alerta Rousseau, querer transformá-la precocemente num adulto, matando, com isso, a alegria e a felicidade própria da infância. A questão não consiste, portanto, nem em diminuir os desejos, nem, muito menos, em ampliar as faculdades, mas sim "em diminuir o excesso dos desejos sobre as faculdades, pondo em perfeita igualdade o poder e a vontade (volonté)" (OC IV, 304; 1992 p. 62).

Neste contexto, o grande desafio da educação natural não reside em ignorar e, muito menos, reprimir os desejos da criança, mas, levando-os em consideração, poder estabelecer a distinção entre os que são reais e aqueles que são de fantasia e, sobretudo, em impedir a invasão racional adulta excessiva no mundo da criança, pois tal invasão nada mais faz do que estimular os desejos de fantasia e, com ele, os vícios, a artificialidade e a corrupção humana.

O projeto de educação natural movimenta-se aqui no fio da navalha: de um lado, precisa evitar a repressão dos desejos da criança, pois, caso contrário, a educação natural se jogaria por inteiro nos braços do moralismo autoritário; de outro, precisa impedir que tais desejos se sobreponham às faculdades, uma vez que isso conduziria a educação natural para o espontaneismo, levando-a a bater de frente com a ideia de liberdade bem regrada (liberté bien réglée). ${ }^{8}$ Trata-se de evitar, como se pode observar, tanto o excesso como a falta e a grande tarefa consiste em proporcionar à criança recursos que a auxiliem na construção de um modo de vida equilibrado, sem que o mesmo se torne reprimido ou por si só abusivo. $\mathrm{O}$ ponto nuclear é que tais recursos, para serem eficientes, não podem estar alicerçados somente na razão e, muito menos ainda, nas lições moralistas do adulto, mas sim na educação pelas coisas, mediada pedagogicamente pela ação do educador. Rousseau insiste, neste contexto, que a referência normativa não deve repousar de modo algum no "capricho dos homens", mas sim no "jugo que a natureza impõe ao homem, o pesado jugo da necessidade (nécessité)" (OC IV, 320; 1992, p. 76).

Por fim, a tensão entre amor de si (amour de soi) e amor próprio (amour propre). Para tratá-la, temos que sair, momentaneamente, do segundo livro e ir para o quarto 
livro do Émile. Tal tensão tem origem, segundo Rousseau, no próprio amor por si mesmo que caracteriza o homem. ${ }^{9}$ Ou seja, a constituição da individualidade (de seu si mesmo) está profundamente vinculada com o amplo sentimento de amor que cada um possui por si mesmo. Este sentimento adquire, por sua vez, nas palavras de Rousseau, uma dupla dimensão, desdobrando-se no sentimento natural originário do amor de si e no sentimento eminentemente social do amor próprio. Além de possuírem origem e significação diferentes, também não desempenham o mesmo papel, tanto no que diz respeito à sociabilidade humana, como, especificamente, à constituição da identidade do homem.

Interessa-nos esclarecer aqui, antes de tudo, o quanto esta dinâmica tensional é importante para o projeto de educação natural e, com isso, o quanto ela é relevante para o conhecimento da criança como criança. Rousseau deixa claro, em inúmeras passagens de sua obra, que não se deve tomar o amor próprio pelo amor de si, porque são duas paixões completamente diferentes, tanto pela sua natureza como pelos seus efeitos. Enquanto o amor de si, profundamente entrelaçado com a piedade, conduz à afetuosidade, o amor próprio conduz ao ódio e à raiva; enquanto o primeiro diz respeito ao homem natural, o segundo refere-se ao homem social. Assim afirma ele, no quarto livro do Émile: "Eis como as paixões ternas e afetuosas nascem do amor de si mesmo, e como as paixões odientas e irascíveis nascem do amor próprio" (OC IV, 493; 1992, p. 237).

No entanto, não podemos compreender adequadamente o papel desempenhado pelo amor próprio na sociabilidade e moralização do homem se considerarmos, como se fosse posição definitiva de Rousseau, a ideia de que só o amor de si possui qualidades positivas e o amor próprio, por sua vez, as qualidades negativas, atribuindo-lhe a fonte exclusiva da maldade humana. Há provas textuais suficientes para mostrar o caráter ambíguo do amor próprio, fato este que conduz Rousseau a atribuir uma reciprocidade tensional entre amor de si e amor próprio. Ele faz isso, a nosso ver, com base em duas teses irrecusáveis, as quais muitas vezes escapam da análise de seus intérpretes: a) a passagem do amor de si para o amor próprio não significa o desaparecimento por completo do primeiro. $b$ ) $\mathrm{O}$ retorno moral do amor de si não significa o desaparecimento ou eliminação do amor próprio, pois a elevação moral daquele implica o confronto com a racionalidade constitutiva do amor próprio.

Isso mostra então que Rousseau pensa a relação entre amor de si e amor próprio como uma relação aporética e não como uma relação de exclusão ou eliminação, e o faz simplesmente pela convicção de que estes dois sentimentos expressam a dupla indeterminação da própria condição humana: em relação à sua base instintiva e à autolegislação de sua razão. Neste sentido, permanece ao homem um espaço de liberdade tanto em relação ao seu determinismo instintivo como à 
capacidade autolegisladora de sua razão. Este espaço livre, associado à ideia de perfectibilité, imputa ao homem sua condição de indeterminabilidade.

O problema, eminentemente pedagógico, que emerge da dinâmica tensional entre amor de si e amor próprio consiste no fato de que é pelo domínio do amor próprio - de suas paixões odientas e rascíveis - que o homem habilita-se a viver socialmente e a conquistar sua moralidade. Ou seja, para que possa fazer suas faculdades evoluir, elevando-as até o nível da moralização, o homem precisa estabelecer uma luta permanente consigo mesmo, visando dominar suas paixões e mantendo-se distante dos vícios. ${ }^{10}$ Trata-se, antes de tudo, da formação de uma fortaleza interior que o faça resistir às seduções que constantemente se lhe aparecem e que podem conduzi-lo ao abismo da maldade. Mas isso é tarefa de uma educação social que, ao dirigir-se fundamentalmente ao jovem, deve formá-lo moralmente, isto é, deve não só evitar o vício, como também ensinar a virtude. Esta educação social representa aquele momento, no Émile, em que o aluno fictício ingressa definitivamente na sociedade, passando a viver na idade da razão e da sabedoria.

Retomando nosso problema, que conotação específica o amor próprio assume na infância e como a educação natural deve tratá-lo? Na infância predomina o sentimento do amor de si. A criança é tendencialmente mais afetuosa do que odienta, mais alegre do que triste, mais sentimental e espontânea do que racional e, com isso, age muito mais movida pelos sentidos do que pela razão. ${ }^{11}$ Embora seja sede também da racionalidade que conduz o homem à reflexão de si mesmo, o amor próprio é inegavelmente a fonte de "paixões odientas e racíveis". Como a criança não está ainda em condições de se apropriar do aspecto construtivo que é inerente ao amor próprio e, por isso, está mais sujeita ao seu aspecto destrutivo, é tarefa da educação natural, neste contexto, mantê-la o máximo possível distante de tal sentimento. Ao fazer isso, ela consegue preservar a criança dos vícios e da artificialidade adulta, garantindo-lhe um contato maior com as coisas e com a natureza.

Confrontando este aspecto mais uma vez com a educação bárbara, fica claro seu limite: ao conceber a criança como um ser mais racional do que sensível, a educação bárbara lhe atribui o amor próprio como sentimento constitutivo de sua estrutura psíquica, sem, no entanto, trabalhar pedagogicamente com os efeitos destrutivos que tal sentimento pode gerar na formação da criança. Dito de outro modo, por conceber a criança como um ser que nasce com sua racionalidade pronta, ela sente-se autorizada a trazer precocemente o sentimento do amor próprio para dentro da infância, mas, simultaneamente, descuidando-se de educar as paixões odientas e racíveis que lhe são inerentes. A educação bárbara torna-se, deste modo, um modelo educacional incapaz de tratar, de maneira pedagogicamente adequada, o aspecto destrutivo do amor próprio. Esta é uma das razões que leva, segundo Rousseau, este tipo de educação a "corromper" e "estragar" nossas crianças. 


\section{A dimensão négative da educação natural}

Diferentemente da educação social, a educação natural deve ser eminentemente negativa. Sendo assim, devemos nos debruçar agora sobre a investigação deste princípio e de seu significado crítico à educação bárbara. Em tal princípio encontramos, certamente, a principal característica da educação natural e nele repousa também sua exigência maior, a saber, em mais evitar o vicio do que em ensinar a virtude. A passagem do segundo livro do Émile na qual o genebrino melhor qualifica, literalmente, a educação natural de negativa é a seguinte: "A educação primeira deve, portanto, ser puramente negativa. Ela consiste não em ensinar a virtude (vertu) ou a verdade (vérité), mas em preservar o coração do vício e o espírito do erro" (OC IV, 323; 1992, p. 80).

É preciso considerar, em primeiro lugar, no que diz respeito ao conteúdo da passagem, que a educação primeira corresponde à educação natural, uma vez que a educação segunda refere-se à educação social, a qual, embora profundamente ligada à educação natural, possui suas especificidades, entre elas a de propriamente ensinar a virtude. No entanto, em segundo lugar, contrariamente à educação social, a educação natural possui, como sua tarefa principal, proteger a criança do vício e do erro. Mas qual é a razão que leva Rousseau a atribuir um papel somente negativo à educação natural? Mais precisamente, por que não se deve ensinar a vertu e a vérité às crianças? De modo provocativo, poderíamos ainda perguntar: Que mal haveria nisso? Uma resposta a estas perguntas só pode ser dada efetivamente na medida em que se esclarecer o significado atribuído por Rousseau à dimensão negativa da educação natural no contexto mais amplo de sua noção de sociedade e de infância. De qualquer forma, como se verá logo a seguir, não deveríamos começar raciocinando com nossas crianças porque elas, além de só poderem chegar ao pensamento pelo uso que fazem de seus sentidos, e não propriamente da razão, nascem em um contexto social profundamente corrompido e artificial, contra o qual precisam ser protegidas.

Com isso, somos levados a inserir, brevemente, o caráter negativo atribuído à educação natural no contexto da noção rousseauniana geral, tanto de sociedade como de infância. A sociedade como ela é significa, aos olhos do genebrino, o mundo das relações humanas inteiramente corrompidas. A dinâmica da configuração social de sua época, como Elias (1983) reconstruiu em detalhes, em seu estudo sobre a sociedade de corte, mostra-se alimentada pela lógica do parecer. Neste contexto, para poder alcançar o prestígio e o reconhecimento social desejado, importa ao homem muito mais parecer ser a qualquer custo do que buscar viver em autenticidade.

Trata-se, portanto, de uma lógica destrutiva, do ponto de vista da constituição das relações humano-sociais, porque empurra os homens para um nível cada 
vez mais artificial de seu comportamento e de suas relações. Este nível crescente de artificialidade põe em risco, por sua vez, toda perspectiva de autenticidade. Ou seja, quando o esforço maior consiste em parecer ser a qualquer custo o que não se é, a busca pela formação autêntica do caráter fica relegada ao segundo plano. Esta situação social mostrou claramente a Rousseau a faceta eminentemente moral de uma profunda problemática social. Neste contexto, ele considerou que o modo mais consequente para enfrentá-la residia no âmbito educacional, mais precisamente na educação das novas gerações, e é por isso que sua preocupação focou-se na infância, mais precisamente na educação das crianças. Não há dúvida de que foi este pano de fundo problemático que o conduziu a esboçar, nos três primeiros livros do Émile, um projeto de educação natural que tem sua âncora na formação integral da infância.

A noção rousseauniana de infância tem, por sua vez, seu eixo de sustentação na ideia de que antes de ser racional, a criança é um ser sensitivo, que constrói suas relações embrionárias com o mundo e consigo mesmo, utilizando-se muito mais dos sentidos do que da razão, isto é, daquele aparato cognitivo mínimo que lhe está disponível. Rousseau formula esta ideia influenciado pela epistemologia empirista em voga na sua época, cuja tese principal concede primazia às percepções e ao papel desempenhado pelos sentidos na aquisição do conhecimento. ${ }^{12}$

O primado atribuído pela epistemologia empirista aos sentidos e às percepções do homem serve de modelo para Rousseau pensar a infância: se tal predomínio ainda ocorre na psique adulta, que possui a estrutura racional mais desenvolvida, quando trazido ao mundo infantil, assume aí uma radicalidade muito maior. $\mathrm{Ou}$ seja, antes de poder formular juízos, a criança sente (possui sensações), sendo, portanto, pelo contexto de sua ação sensitiva que ela começa a estabelecer minimamente suas relações cognitivas com o mundo.

Mais ainda, a tese do primado da "razão sensitiva" em relação à "razão intelectiva" põe a exigência, fundamental tanto do ponto de vista epistemológico como pedagógico, de que para poder alcançar a condição de um ser racional, capaz de fazer uso de sua capacidade de pensar, a criança precisa ser considerada seriamente em sua constituição sensitiva e, sobretudo, educada em sua dimensão corporal e no uso adequado de seus sentidos. Portanto, a conviç̧ão de fundo da educação natural repousa na ideia de que tanto o corpo como os sentidos só poderão assumir o papel relevante e insubstituível que lhes cabe na progressiva formação afetiva, cognitiva e moral da criança, quando forem adequadamente educados. Daí surge a importância da "física experimental" para dar conteúdo e forma pedagógica à educação natural.

Temos, com isso, uma dupla situação esclarecedora da ênfase dada pelo genebrino à dimensão negativa da educação natural: por um lado, a artificialidade 
social reinante; por outro, a fragilidade da criança, como um ser inicialmente mais sensível do que racional, para fazer frente ao alto nível doentio e insuportável de artificialidade humana e social. Ou seja, considerando então, simultaneamente, que a sociedade corrompida "estraga" a criança - mais deseducando do que educando - e a fragilidade e a posição indefesa da condição infantil, o melhor de um projeto educacional que vise ensinar a pensar - isto é, que vise à formação para a autonomia - é, nesta situação, evitar que a criança seja jogada, irrefletida e apressadamente, no gigantesco redemoinho artificial das relações sociais. Em síntese, a dimensão negativa da educação natural significa, então, no fundo, para Rousseau, um projeto de proteção da criança que deve ser meticulosamente planejado pelo educador, do ponto de vista pedagógico, para evitar que ela seja forçada a aprender coisas que estão fora de sua capacidade intelectiva mínima; ou que ela própria seja exposta a determinadas situações que venham viciar irreversivelmente seu comportamento e seu modo de ser. ${ }^{13}$

Penso que, com isso, fica esclarecido o maior princípio da educação natural, sobre o qual se gerou muita polêmica e muito mal entendido. O principal deles é a acusação, que pesa contra Rousseau, de ter pretendido, ao atribuir caráter manifestamente negativo ao seu projeto de educação natural, o afastamento de seu aluno fictício do convívio social e, com isso, de tê-lo isolado no interior da floresta. $\mathrm{O}$ genebrino nunca escondeu sua preocupação com o fato de que as crianças fossem jogadas precocemente na convivência social adulta, sem ter o devido acompanhamento. Além disso, como vimos, e isso nos parece ser a ideia mais importante, é parte de sua convicção epistemológico-pedagógica de fundo - a qual ele não poderia renunciar sob a condição de pôr em risco o ideal de seu próprio projeto - a ideia de que a criança aprende inicialmente pelos sentidos e que seu contato com a ordem das coisas, além de melhor aguçá-la cognitivamente, também tem, do ponto de vista moral, a grande vantagem de evitar a corrupção precoce de seu caráter. Mas isso não significa, obviamente, que tanto o desenvolvimento das potencialidades intelectuais como a conquista progressiva da moralização do caráter só pudessem ser obtidos mediante o isolamento do educando.

Por fim, é preciso considerar, contra tal objeção, que o aluno fictício, mesmo na situação limite, extrema, nunca estaria sozinho, pois contaria sempre com a companhia atenta de seu governante. No entanto, para que a educação dirigida à infância possa ser realmente natural, o próprio governante precisa delimitar seu mundo social. Aqui está uma indicação crucial, do ponto de vista metodológico, para que o educador possa tratar a criança como criança: evitar agir com ela como se estivesse simplesmente agindo com outro adulto. Isso exige do educador, então, entre outras coisas, o domínio máximo de todas aquelas suas inclinações adultas que possam viciar e corromper a criança, entre as quais a de querer determinar autoritariamente 
o comportamento dos outros, prescrevendo-lhes a todo o instante o que devem fazer ou deixar de fazer. Ou, ao adotar um procedimento oposto, deixar a criança fazer o que bem entender, contribuindo para que ela se torne dominadora e tirânica. Ou seja, para poder mediar pedagogicamente a relação da criança com a ordem das coisas (ordre des choses) e com o conjunto de resistências que tal ordem lhe opõe, o educador precisar estar bem formado e isso significa, no contexto de uma educação natural, saber filtrar adequadamente seu próprio mundo social, evitando fazer chegar até a criança aqueles aspectos que possam corromper seu caráter.

Aqui se localiza uma enorme exigência feita ao educador, a qual poderia ser descrita, etnometodologicamente, como uma postura de se despir o máximo possível de sua própria cultura, para poder investigar a cultura estranha. Ou seja, sem seu próprio estranhamento inicial, o educador não pode compreender o educando como um estranho e alguém diferente dele mesmo. No entanto, esse processo de estranhamento, quando visto hermeneuticamente, ${ }^{14}$ se mostra como procedimento eficaz de conhecimento de si mesmo. Em síntese, ao levar a sério, pedagogicamente, a exigência de buscar conhecer a criança como criança - o educando como educando -, o adulto (educador) nada mais está do que propiciando condições para se conhecer a si mesmo. Contudo, nos termos da educação natural, a relação entre educador e educando só pode significar realmente esta descoberta de si mesmo quando for mediada pela relação autêntica com o outro, isto é, quando o educando (criança) for tomado como ser sensitivo, que só desenvolve progressivamente sua estrutura cognitiva porque é permanentemente instruído em sua relação com o mundo das coisas.

\section{Notas}

1. O livro Jean-Jacques Rousseau. Ein pädagogisches Porträt, escrito por Alfred Schäfer (2002), é uma das melhores abordagens atuais sobre o problema da educação negativa no Émile. Numa passagem do terceiro capítulo da referida obra, dedicado exclusivamente para tratar do tema em questão, o autor afirma o seguinte: “'Educação natural' ou 'educação de um homem natural' mediante condições sociais significa então que o educador deve abrir ao educando a possibilidade de alcançar a identidade consigo mesmo (como equilíbrio entre seus desejos e suas capacidades) em cada nível de seu desenvolvimento. Somente assim seu autoestranhamento pode ser evitado" (p. 61).

2. Todas as citações da obra de Rousseau serão feitas como a que seguiu, indicando-se primeiro a obra no original, abreviada como OC, seguida do volume em romano e da paginação em arábico; por fim, o ano e a paginação da tradução portuguesa empregada.

3. Sobre a contribuição de Locke para o pensamento pedagógico do século XVIII e, especificamente, para o pensamento de Rousseau, ver, entre outros, Lebede (s/e) e Rhyn (2003).

4. Assim afirma Rousseau no segundo livro do Émile: "Raciocinar com as crianças era a grande máxima de Locke; é a que está mais em voga hoje; seu êxito não me parece, entretanto, muito de molde a justificar-lhe o crédito" (OC IV, 317; 1992, p. 74).

5. Rousseau ocupa as páginas iniciais do segundo livro do Émile para criticar a pedagogia de sua época, definindo-a textualmente de éducation barbare (OC IV, 301; 1992, p. 60). 
6. Sobre a noção de perfectibilidade em Rousseau, ver o importante estudo de Benner e Brüggen (1996, p. 12-48).

7. O emprego da expressão "natureza humana" só faz sentido, no pensamento de Rousseau, quando isenta da pressuposição metafísica de fundo que a concebe como uma essência racional pronta. A crítica de Rousseau à antropologia filosófica clássica leva-o também à relativização da oposição convencional entre razão e sensibilidade, incluindo, entre eles, como algo intermediário ou mediador, a noção de consciência. Sobre isso, ver especialmente a "profissão de fé do vigário saboiano", no quarto livro do Émile.

8. No contexto da crítica à éducation barbare, também há uma preocupação de Rousseau com a permissividade da "educação habitual dos ricos" (l'éducation façonniére des riches - OC IV, 312; 1992, p. 70) que estimulava excessivamente os desejos da criança em detrimento de suas necessidades reais. Isso seria típico de uma sociedade artificial que objetivava preparar a criança filha de ricos para o mando e o domínio tirânico sobre os outros. Nesse sentido, a educação natural deveria fazer valer, também contra esta tendência, o princípio da necessidade baseado na educação pelas coisas. A crítica à éducation barbare e à éducation des riches orienta-se não pelos caprichos dos homens, mas sim pela nécessité des choses. Esta é a premissa fundamental da educação natural, que visa formar antes de tudo o homem, tomando-o como ponto de partida irrenunciável da formação de sua cidadania.

9. Para uma abordagem atualizada sobre o significado da problemática do amor de si e do amor próprio no pensamento de Rousseau, ver o estudo de Neuhouser (2008).

10. Neste ponto manifesta-se, nitidamente, a influência do conceito normativo de natureza, de procedência estoica.

11. Com o avanço das pesquisas sobre o psiquismo infantil, no século $X X$, sobretudo a partir do trabalho de Donald Winnicott, seríamos levados a relativizar muitos aspectos da compreensão do mundo da criança, a partir da dinâmica tensional entre o amor de si e o amor próprio; e, a meu ver, o mais importante: estaríamos mais bem habilitados para compreender as patologias que constituem o próprio psiquismo infantil.

12. Trata-se aqui, evidentemente, de uma determinada versão da epistemologia empirista ou, sobretudo, de uma determinada leitura da teoria do conhecimento de Locke, que é feita pelo materialismo francês e que, de certo modo, também influencia Rousseau. O terceiro capítulo da obra A filosofia do Iluminismo, de Ernst Cassirer (1992), ainda continua sendo uma referência clássica para este tema.

13. Este aspecto negativo da educação natural torna ainda mais claro o papel indispensável que a ideia de natureza desempenha nas convicções pedagógicas de Rousseau: como a sociedade é artificial e a criança é indefesa, a inserção da criança na "ordem da natureza" é a melhor forma de educá-la. Portanto, sob este aspecto, a natureza é a principal pedagoga do homem, quando este se encontra em sua fase infantil. Sobre a conexão entre natureza e vida boa, ver o estudo de Cooper (1999).

14. Sobre a abordagem de problemas educacionais numa perspectiva hermenêutica, incluindo a relação entre educador e educando, ver o mais recente livro de Hans Georg Flickinger: A caminho de uma pedagogia hermenêutica (2010).

\section{Referências}

BENNER, D.; BRÜGGEN, F. Das Konzept der Perfectibilité bei Jean-Jacques Rousseau. Ein Versuch, Rousseaus Programm theoretischer und praktischer Urteilsbildung problemgeschichtlich und systematisch zu lesen. In: HANSMANN, O (Ed.). Seminar: der pädagogische Rousseau. Weinheim: Deutscher Studien, 1996. v. 2, p. 12-48.

CASSIRER, E. A filosofia do Iluminismo. Trad. Álvaro Cabral. Campinas: Unicamp, 1992. 
COOPER, L.D. Rousseau: nature and the problem of the good life. Pennsylvania: Pennsylvania State University, 1999.

ELIAS, N. Die höfische Gesellschaft. Frankfurt am Main: Suhrkamp, 1983.

FLICKINGER, H.G. A caminho de uma pedagogia hermenêutica. Campinas: Autores Associados, 2010.

LEBEDE, H. Locke und Rousseau als Erzieher. Berlin: Wilhelm Borngräber, [s.d.].

NEUHOUSER, F. Rousseaus Theodicy of 'Amour Propre': evil, rationality and the drive for recognition. Oxford: Oxford University, 2008.

RHYN, H. John Locke. In: TENORTH, H.E. (Ed.). Klassiker der Pädagogik: Von Erasmus bis Helene Lange. München: C. H. Beck, 2003. p. 60-71.

ROUSSEAU, J.J. Ouvres complètes. Paris: Gallimard; Bibliothèque de la Pléiade, 1964. v. 3.

ROUSSEAU, J.J. Ouvres completes. Paris: Gallimard; Bibliothèque de la Pléiade, 1969. v. 4.

ROUSSEAU, J.J. Discurso sobre a origem e os fundamentos da desigualdade entre os homens. Trad. de Lourdes Santos Machado. São Paulo: Abril Cultural, 1978.

ROUSSEAU, J.J. Emilio ou Da educação. Trad. de Sérgio Millet. Rio de Janeiro: Bertrand Brasil, 1992.

SCHÄFER, A. Jean-Jacques Rousseau: Ein pädagogisches Porträt. Weinheim; Basel: Beltz, 2002.

Recebido em 5 de abril de 2012.

Aprovado em 26 de junho de 2012. 